
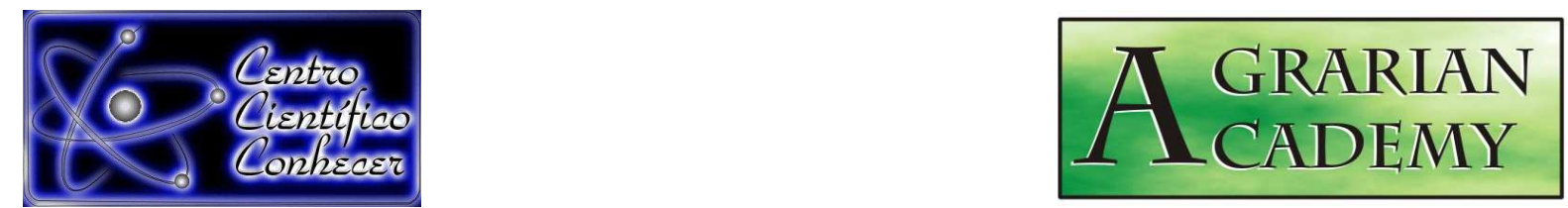

\title{
A IMPORTÂNCIA DO COCO BABAÇU PARA A COMUNIDADE ESCOLAR E EXTRATIVISTA NO MUNICÍPIO DE SÃO JOÃO DO ARRAIAL/PI
}

\section{Guilherme Sousa da Silva1; Maria Eliane Mota Barroso²; Domingos Lucas dos Santos Silva ${ }^{3}$; Gonçalo Mendes da Conceição ${ }^{4}$}

${ }^{1}$ Graduado em Ciências Biológicas, Pós-Graduando em Educação e Ensino de Ciência, IFMA/Campus Caxias, Caxias/MA, Brasil (guilhermecx.cx@hotmail.com)

${ }^{2}$ Graduada pelo Programa de Formação de Professores da Educação Básica/PARFOR, Curso de Licenciatura Plena em Ciências Biológicas, Universidade Estadual do Piauí/UESPI.

${ }^{3}$ Mestre em Biodiversidade, Ambiente e Saúde, CESC/UEMA, Caxias/MA, Brasil.

${ }^{4}$ Professor Dr. da Universidade Estadual do Maranhão/UEMA, Centro de Estudos Superiores de Caxias/CESC, Programa de Pós-Graduação em Biodiversidade, Ambiente e Saúde/PPGBAS, Caxias/MA, Brasil.

\section{Recebido em: 15/07/2016 - Aprovado em: 29/07/2016 - Publicado em: 31/08/2016} DOI: 10.18677/Agrarian_Academy_2016_001

\section{RESUMO}

O babaçu é uma importante palmeira presente no Brasil, distribuindo-se por 18 milhões de hectares em todo país. É constituído por um conjunto de espécies do gênero Attalea sendo as espécies de maior representação: $A$. speciosa e $A$. vitrivir. $\mathrm{Na}$ região dos cocais, no Nordeste brasileiro, vários municípios atrelam a economia ao coco babaçu. Assim o trabalho teve como objetivo caracterizar a importância do coco babaçu para a comunidade escolar no município de São João do Arraial/PI. Para a realização desta pesquisa, fez-se um levantamento bibliográfico com informações sobre o tema em estudo. Para coleta de dados foram aplicados questionários com alunos da escola Municipal Dirceu Mendes Arcoverde e entrevistas com famílias extrativistas do coco babaçu no município, as perguntas eram fechadas, adaptadas e aprimoradas de pesquisas correlatas sobre a valorização do babaçu, sendo observadas as especificidades das características locais. A partir dos dados obtidos foi demonstrado que o fruto do babaçu tem diversas formas de aproveitamento, podendo ser colocado em destaque na alimentação escolar, e de excelente aproveitamento aos alunos. Quanto às entrevistas observou-se que o extrativismo do coco é essencial para subsistência da renda familiar. Assim pode-se observar a importância do fruto dentro do município sendo reconhecido como principal fonte extrativista.

PALAVRAS-CHAVE: Extrativismo; Mesocarpo; Produção econômica. 


\title{
THE COCONUT BABASSU IMPORTANCE FOR SCHOOL COMMUNITY AND ARE IN EXTRACTIVE MUNICIPALITY OF JOHN ARRAIAL/PI
}

\begin{abstract}
The babassu palm is an important presence in Brazil, being distributed by 18 million hectares across the country. It consists of a number of species of the genus Attalea being the species most represented: $A$. speciosa and $A$. vitrivir. In the area of coca crops in the Brazilian Northeast, several municipalities atrelam the economy the babassu coconut. Thus the study aims to characterize the importance of babassu coconut to the school community in the municipality of São João do Arraial/PI. For this research, there was a literature with information on the subject under study. For data collection questionnaires were applied to students of the Municipal School Dirceu Mendes Arcoverde and interviews with extractive families babassu coconut municipality, the questions were closed, adapted and enhanced related research on specific local characteristics appreciation of babassu being observed. From the data obtained has shown that the fruit of the babassu has several ways to use and can be highlighted on the school food, and great use to students. The interviews revealed that the coconut extraction is essential for survival of the family income. Thus one can see the importance of the fruit within the municipality is recognized as the main source extraction.
\end{abstract}

KEYWORDS: Extraction; mesocarp; economic output.

\section{INTRODUÇÃO}

O babaçu é uma importante palmeira presente no Brasil, distribuindo-se por 18 milhões de hectares em todo país. É constituído por um conjunto de espécies do gênero Attalea sendo as espécies de maior representação: $A$. speciosa e $A$. vitrivir. Como espécie típica precursora, alastrou-se espontaneamente por uma grande área da região Nordeste chegando a ter mil indivíduos por hectare. A palmeira pode atingir até $20 \mathrm{~m}$ de altura, estipe característico por apresentar restos das folhas velhas que já caíram em seu ápice. Folhas com até oito metros de comprimento arqueados. As flores desta espécie de palmeira são creme amarelada, aglomeradas em cachos. Em cada palmeira pode apresentar até seis cachos (VIVA TERRA, 2013).

A palmeira de coco babaçu é uma planta que faz parte da vegetação secundária, ou seja, a partir do momento que ocorre o desmatamento, seguido do fogo, para o plantio de roçados, a germinação dos frutos é potencializada. As plantas de babaçu se desenvolvem bem em regiões de clima quente, e ocorrem principalmente nos estados do Maranhão, Piauí, Mato Grosso e áreas isoladas dos estados do Ceará, Pernambuco e Alagoas. São encontradas também na Bolívia, Guianas e Suriname. A propagação da planta é feita através de sementes. A espécie Attalea phalerata ocorre de maneira descontínua em quase todo território maranhense e piauiense e em algumas áreas de ocorrência esparsa no Noroeste da região Nordeste onde essas populações diminuem (BALICK \& PINHEIRO, 2002; PINHEIRO, 2011).

De todas as partes da planta, o fruto é a que apresenta o maior potencial econômico, chegando a produzir mais de 64 subprodutos. O óleo da amêndoa é o 
produto do babaçu mais utilizado e comercializado no mercado, rico em ácido láurico, é aproveitado em larga escala na fabricação de sabão, sabonetes, e cosméticos em geral. Na culinária o uso é muito restrito, uma vez que não compete em preço e qualidade nutricional com outros óleos, como o de soja, girassol e amendoim (SOLER et al., 2007).

A cadeia produtiva do babaçu é uma das mais representativas do extrativismo vegetal no Brasil, em razão da área de abrangência da palmeira (13 a 18 milhões de hectares em 279 municípios, situados em 11 Estados), bem como das inúmeras potencialidades e atividades econômicas que podem ser desenvolvidas a partir desta, enfatizando a importância para famílias que sobrevivem da agricultura de subsistência associada à exploração do coco, e da forte mobilização social e política em favor do acesso livre aos babaçuais (NOLETO, 2012).

O incentivo a atividade extrativista como forma de mudanças no quadro de pobreza, conflitos agrários e degradação ambiental, passa pela compreensão das falhas encontradas na produção. Dessa forma busca-se uma forma equilibrada entre explorar e preservar o ambiente como patrimônio natural e fonte de sustento para a população que depende deste bioma. E importante que esta reflexão saia do campo do conhecimento popular e parta para o campo do conhecimento técnico científico e que possa beneficiar economicamente a população (MEDEIROS et al., 2011).

O PAA (Programa de Aquisição de Alimentos) está abrindo novas oportunidades para as quebradeiras de coco babaçu. Por esse programa, o governo compra alimentos produzidos localmente e os distribui para escolas, creches e outras instituições. Desse modo, não somente os agricultores e as quebradeiras têm a venda da produção garantida, como também crianças, idosos e outras pessoas necessitadas alimentam-se melhor, de produtos saudáveis cultivados no local de origem do produto, assim o ambiente escolar é bastante privilegiado pela utilização extrativista do coco (BARTONE, 2011).

$\mathrm{Na}$ região Leste e Nordeste do Maranhão e o Oeste e Noroeste do Piauí localiza-se uma zona de grande abundância de babaçuais denominada de Mata dos cocais, e tratando-se do Piauí especificamente no município de São João do arraial é muito comum encontrar essa palmeira, principalmente, na zona rural. A economia da cidade é voltada ao extrativismo do coco babaçu, tudo se aproveita do fruto. Dessa forma o trabalho teve como objetivo conhecer a importância do coco babaçu para a comunidade escolar e extrativista no município de São João do Arraial/PI reconhecendo as potencialidades econômicas do babaçu e sua utilização no município.

\section{MATERIAL E MÉTODOS}

São João do Arraial é um município do estado do Piauí. Localiza-se na microrregião do Baixo Parnaíba Piauiense, mesorregião do Norte piauiense, sendo criado em 1997 (ASMPA, 1992). No território do município de São João do Arraial localiza-se a Escola Municipal Dirceu Mendes Arcoverde, que funciona em prédio próprio e esta localizada no povoado Santa Maria, sendo um dos mais importantes centros educacionais do município. A escola foi construída no ano de 1970 e em fevereiro de 1998 foi recuperada e no ano de 2010 foi ampliada. A escola possui: cinco salas de aula, dois banheiros, um pátio, uma diretoria, uma cantina, um deposito e uma pequena sala de recursos multifuncionais. 
A escola possui um quadro de 23 funcionários sendo um diretor, um secretário escolar, um coordenador pedagógico, 13 professores, três vigias, duas merendeiras e duas zeladoras. A escola oferece ensino infantil (creche e pré-escola) e ensino fundamental de $1^{\circ}$ ano ao $9^{\circ}$ ano nos turnos manhã e tarde com 156 alunos matriculados.

A principal associação extrativista de coco babaçu da região é a Associação de Mulheres Trabalhadoras do Coco Babaçu da Micro Região do Baixo Parnaíba Piauiense/AMTCOB, a mesma começou a funcionar em 2004. Está organizada de forma regional e territorial e nove municípios do baixo Parnaíba fazem parte. Os componentes da Associação são mulheres quebradeiras de coco atualmente composta por 500 mulheres. A extração do mesocarpo é feita em unidades como na casa do grupo de mulheres quebradeiras de coco babaçu, o mesocarpo é extraído do coco verde, vale ressaltar que antes esse processo era feito de forma artesanal, ou seja, manual e atualmente o grupo possui máquinas adquiridas através de órgãos estaduais e federais para melhoria do trabalho das quebradeiras de coco da comunidade.

Para a realização desta pesquisa, fez-se um levantamento bibliográfico com informações sobre o tema em estudo, fazendo-se fichamentos desses materiais para facilitar o entendimento da pesquisa. Foram aplicados questionários aos alunos da Escola Municipal Dirceu Mendes Arcoverde e realizadas entrevistas com famílias extrativistas de coco babaçu da região, partindo da observação da importância dada ao coco babaçu no município e sua inclusão na merenda escolar. A coleta dos dados através de questionário com os alunos foi baseada em perguntas fechadas, adaptadas e aprimoradas de pesquisas correlatas sobre a valorização do babaçu. $O$ questionário, segundo GIL (1999), pode ser definido como a técnica de investigação composta por um número mais ou menos elevado de questões apresentadas por escrito às pessoas, tendo por objetivo o conhecimento de opiniões, crenças, sentimentos, interesses, expectativas e situações vivenciadas.

$\mathrm{Na}$ aplicação dos questionários com os alunos, os mesmos foram abordados em sala de aula e foram esclarecidos da pesquisa realizada e entregues termos de consentimento para avaliação dos responsáveis estabelecendo a permissão ou não dos alunos no trabalho, já que os mesmos são menores de idade. Após a assinatura do termo de consentimento pelos responsáveis, 25 alunos da escola, de turmas do $6^{\circ}$ ao $8^{\circ}$ ano do ensino fundamental participaram da pesquisa, o questionário constituía-se de nove questões fechadas abordando duas questões direcionadas à caracterização do alunado e sete tratando-se da importância do coco babaçu para a escola. Todos os alunos responderam de forma organizada e ciente das suas opiniões.

Para o estudo com famílias extrativistas, foi utilizado o método de entrevistas diretas, para verificação dos dados. Levando em consideração que a entrevista é uma técnica de coleta de dados estabelecendo uma forma racional de conduta do pesquisador, previamente estabelecida, para dirigir com eficácia um conteúdo sistemático de conhecimentos, de maneira mais completa possível, com o mínimo de esforço de tempo (ROSA \& ARNOLDI, 2006). Para a realização da pesquisa reuniu-se três famílias extrativistas de coco babaçu, atuando em um contingente de 31 pessoas entrevistadas pertencentes à comunidade, a mesma agrupa cerca de 50 extrativistas de coco babaçu, que foram escolhidas pela disponibilidade e ação no prática extrativista. Foram elaboradas oito questões fechadas para as mesmas com forma livre de respostas, para debates em torno do tema das questões, todas as 
questões estavam voltadas a temática da utilização do coco babaçu pelas famílias. Nas entrevistas todos concordaram com alguma alternativa proposta pela pergunta onde argumentavam e debatiam seus pontos de vista sobre o tema discutido.

Após a obtenção dos dados do questionário e da entrevista, estes foram analisados através Microsoft Excel 2010, os dados foram organizados, tabulados e sumarizados para a elaboração dos gráficos.

\section{RESULTADOS E DISCUSSÃO}

As duas primeiras questões caracterizaram 0 alunado questionado, observando que dos 25 alunos entrevistados $24 \%$ (6/25) são do sexo masculino e $76 \%(19 / 25)$ do sexo feminino, verificando uma predominância de mulheres, com idade variando de 12 a 16 anos. Os questionários foram aplicados aos alunos do $6^{\circ}$ ao $8^{\circ}$ ano, com a autorização dos pais, 10 alunos pe rtencem ao $6^{\circ}$ ano, sete alunos ao $7^{\circ}$ ano e oito alunos ao $8^{\circ}$ ano.

As próximas questões foram de cunho investigativo, analisando a importância do coco babaçu para os alunos entrevistados dentro do contexto escolar. Analisando Quando os alunos foram questionados se tinham conhecimento da importância do babaçu na comunidade (Fig.1) , verificou-se que 92\% (23/25) responderam que sim enquanto que $8 \%(2 / 25)$ responderam que não sabiam da importância do babaçu para a comunidade. O babaçu é importante através de seus aspectos ecológicos, sociais, econômicos, ambientais, bem como das inúmeras potencialidades e atividades econômicas que podem ser desenvolvidas. O babaçu é muito conhecido entre populações tradicionais brasileiras, e dependendo da região, pode ter várias denominações populares (CARRAZZA et al., 2012).

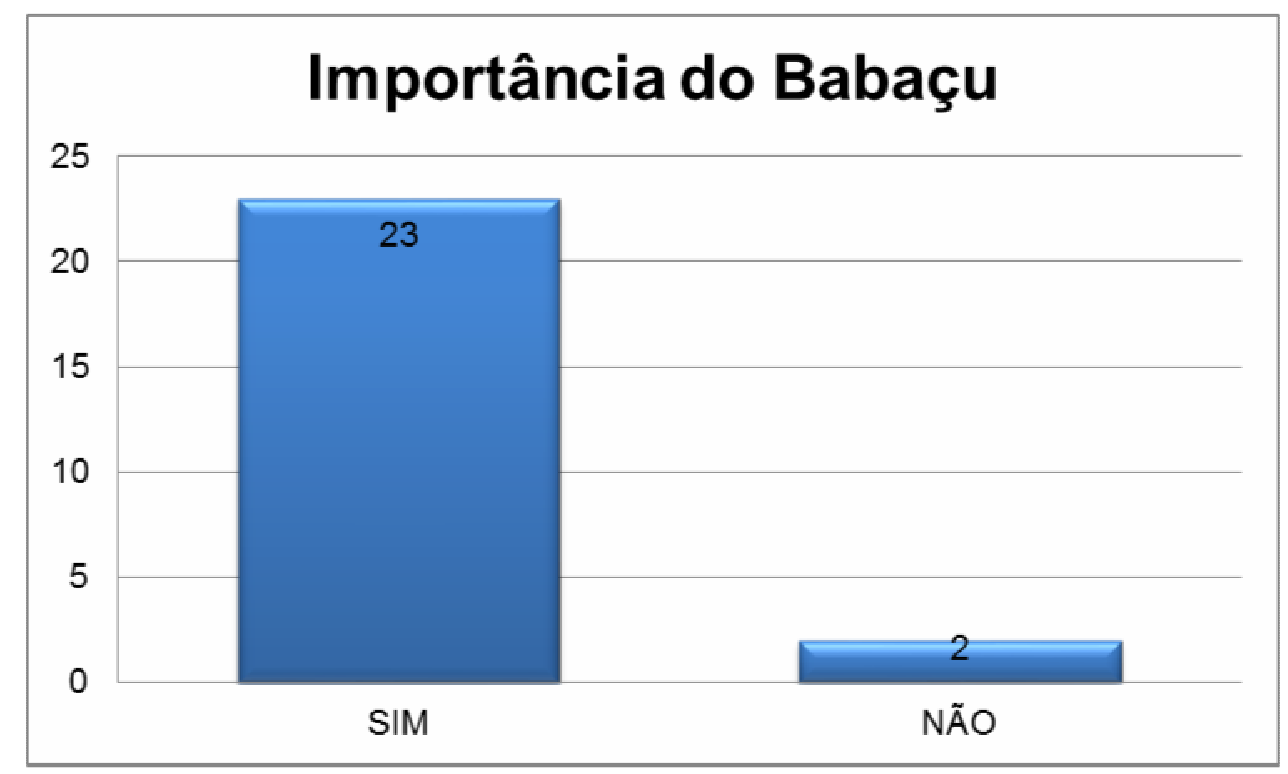

FIGURA 1. Avaliação da importância do coco babaçu para os alunos da Escola Municipal Dirceu Mendes Arcoverde.

Foi perguntado aos entrevistados se gostavam da merenda que é servida na escola (Fig.2), já que esta possui derivados do coco babaçu na composição, verificou-se que $96 \%$ (24/25) dos alunos gostam, enquanto que 4\% (1/25) não gosta da merenda escolar. A merenda escolar é um elemento motivador da frequência na 
escola, pois por falta de alimentação em casa, boa parte dos alunos frequentam o ensino público motivados pela merenda. Então sempre é necessário avaliar a qualidade desse alimento, já que este frequentemente representa a única refeição diária de muitas crianças. Um alimento pode ser considerado como de boa aceitabilidade, quando preenche as expectativas da maior parte dos alunos com relação às características sensoriais: aparência, cor, aroma, consistência ou textura e sabor. O teste de aceitabilidade é importante para verificar o conteúdo nutricional, verificar a inclusão de ingredientes não interessantes para o grupo, verificar o rendimento das preparações e buscar padronização das receitas em cada escola (BASAGLIA et al., 2015).

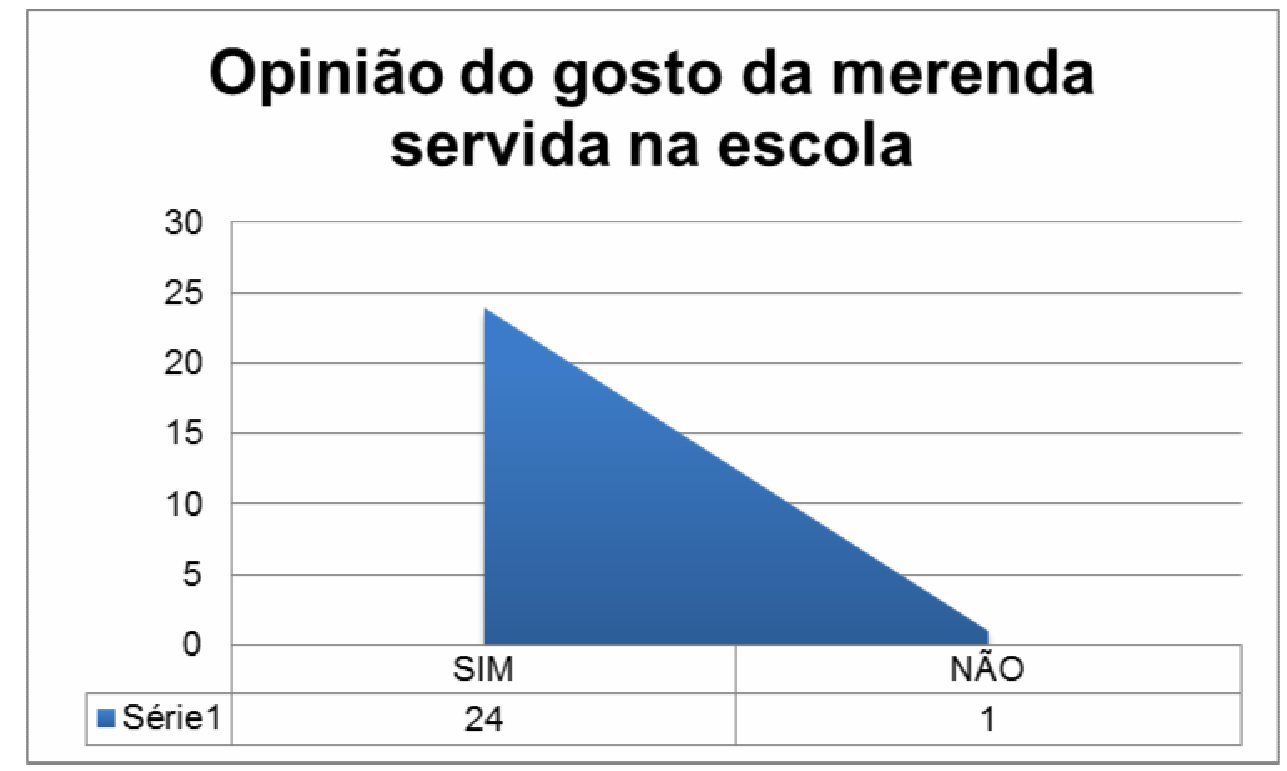

FIGURA 2. Resposta dos alunos quanto a aceitação da merenda na escola Municipal Dirceu Mendes Arcoverde.

O babalate é um tipo de chocolate feito do mesocarpo do coco babaçu e é servido na merenda escolar. Os entrevistados quando perguntados se gostavam do babalate responderam sim, $80 \%(20 / 25)$ dos alunos gostam do babalate enquanto $20 \%(5 / 25)$ dos alunos não gostam (Fig. 3). O babalate é feito do mesocarpo, fibra existente entre a casca do babaçu e a amêndoa. Depois de pilada, a massa é cozida com leite e açúcar, transformando-se em chocolate de babaçu (FELIZARDO, 2016). A farinha do mesocarpo é utilizada em alimento de pessoas que utilizam o amido do mesocarpo para produzir mingaus, bolos e remédios, é recomendado empiricamente para o tratamento de várias doenças. O uso medicinal tem provocado o aumento do uso do mesocarpo na culinária (PINHEIRO, 2011).

No Maranhão, o coco babaçu, foi introduzido na alimentação escolar pelo Programa Casa da Agricultura Familiar Beneficiadora, na forma de achocolatado de farinha de mesocarpo, estimulando as prefeituras a adquirirem dos agricultores locais cadastrados pelos Conselhos Municipais. Pode-se observar na região, produtores inovando e se capacitando para ofertar este e outros produtos aos programas de alimentação escolar (CARVALHO et al., 2009; CASTRO, 2009; AROUCHA, 2012). 


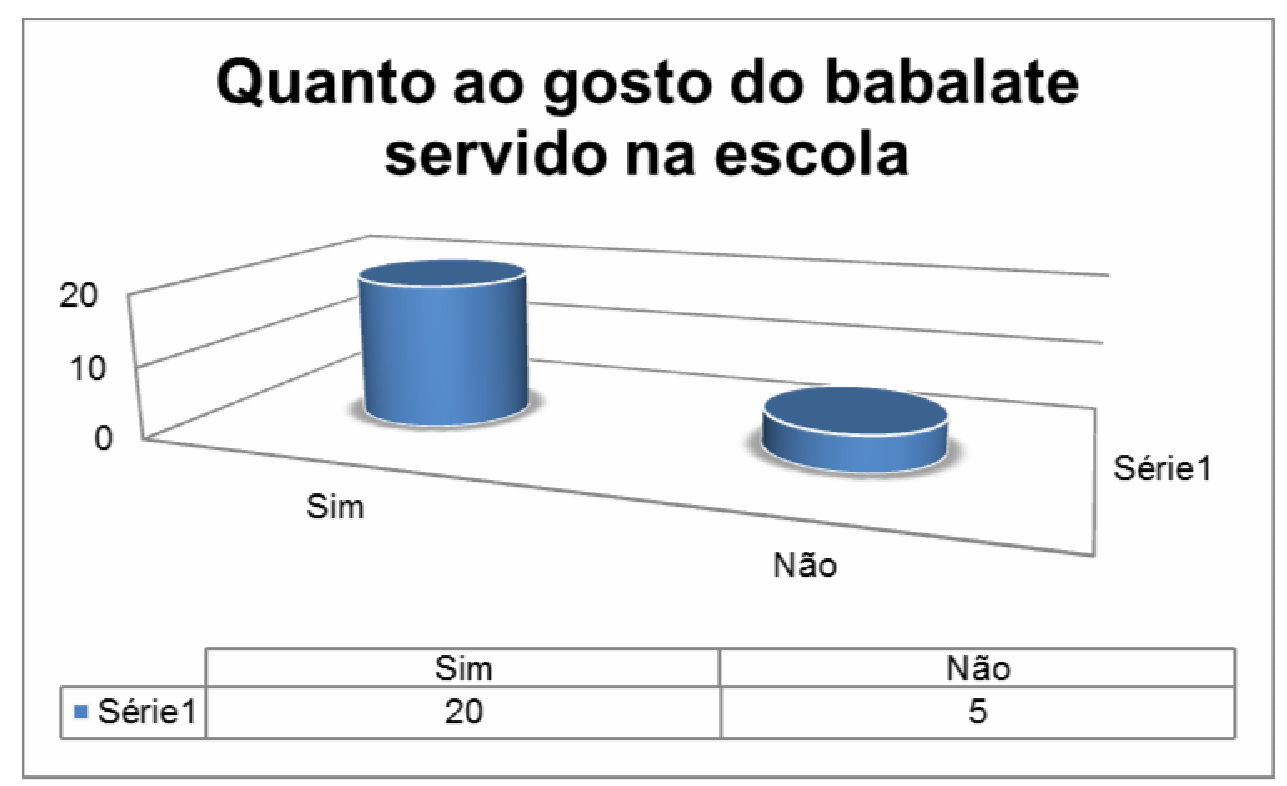

FIGURA 3. Opinião sobre a aceitação ou não do babalate na merenda escolar dos alunos entrevistados.

Analisando ainda a aplicação do babalate na merenda escolar, questionou-se o sabor do babalate, verificou-se que $80 \%$ (20/25) dos alunos responderam que é bom enquanto $20 \%$ (5/25) responderam que era ruim (Fig. 4). Para a produção do Babalate, são necessários vários cuidados para preservação do sabor e da qualidade do alimento. Todo equipamento e utensílio utilizado em produtos do mesocarpo do coco babaçu que possa entrar em contato com o alimento, deve ser confeccionado de material não tóxico, isento de odores e sabores que sejam absorvidos pelo alimento, e deve ser resistente à corrosão e a repetidas operações de limpeza e desinfecção. Deve-se evitar o uso de madeira e de outros materiais que não possam ser limpos e desinfetados adequadamente. O local de estocagem dos utensílios deve ser limpo e apropriado para este fim, sem riscos de contaminação após a limpeza (CARRAZZA et al., 2012).

\section{Quanto ao sabor do babalate}

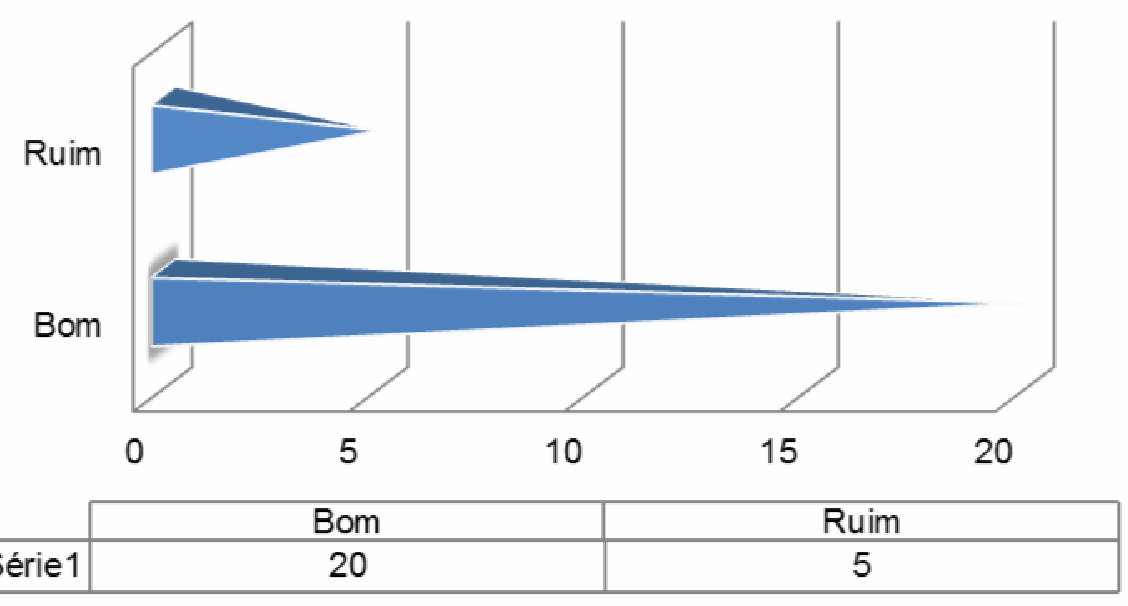

FIGURA 4. Opinião dos alunos sobre o sabor do babalate na merenda escolar 
Uma das perguntas feitas aos alunos foi: Sabem de onde é extraído o mesocarpo do coco babaçu? (Fig.5) Verificou-se que $76 \%$ dos alunos sabiam de onde era extraído o mesocarpo, enquanto que $24 \%$ não sabiam. No babaçual, é feita a primeira seleção, apenas dos cocos maduros e sadios, da safra mais recente (caídos ou derrubados). Na unidade de processamento é realizada a segunda seleção, dos cocos perfeitos, sem marcas ou sinais de roedores. Aconselha-se que logo após o coco seja lavado e o descascamento é tradicionalmente feito à mão, com auxílio de uma faca, mas pode também ser feito com o uso de um descascador. Retira-se a casca (epicarpo) do coco, deixando a massa (mesocarpo) exposta para que seja extraída. A retirada dos flocos do mesocarpo deve ser feita em cima de uma mesa alta e forrada, em ambiente coberto e protegido de insetos e poeira. $O$ coco sem a casca (epicarpo) é colocado sobre a mesa onde recebe golpes de porrete para desprender os flocos. Passando pelos processos finais de secagem, moagem e peneiramento (CARRAZZA et al., 2012).

A produção do mesocarpo do babaçu para alimentação humana obedece a critérios rigorosos de sanidade do produto, por isso, os flocos do mesocarpo devem ser extraídos apenas de cocos maduros sem marcas ou sinais de roedores. $O$ mesocarpo representa cerca de $20 \%$ do fruto sendo composto por até $60 \%$ de amido, $20 \%$ de fibras e $20 \%$ de outras substâncias em pequenas quantidades (PINHEIRO, 2011).

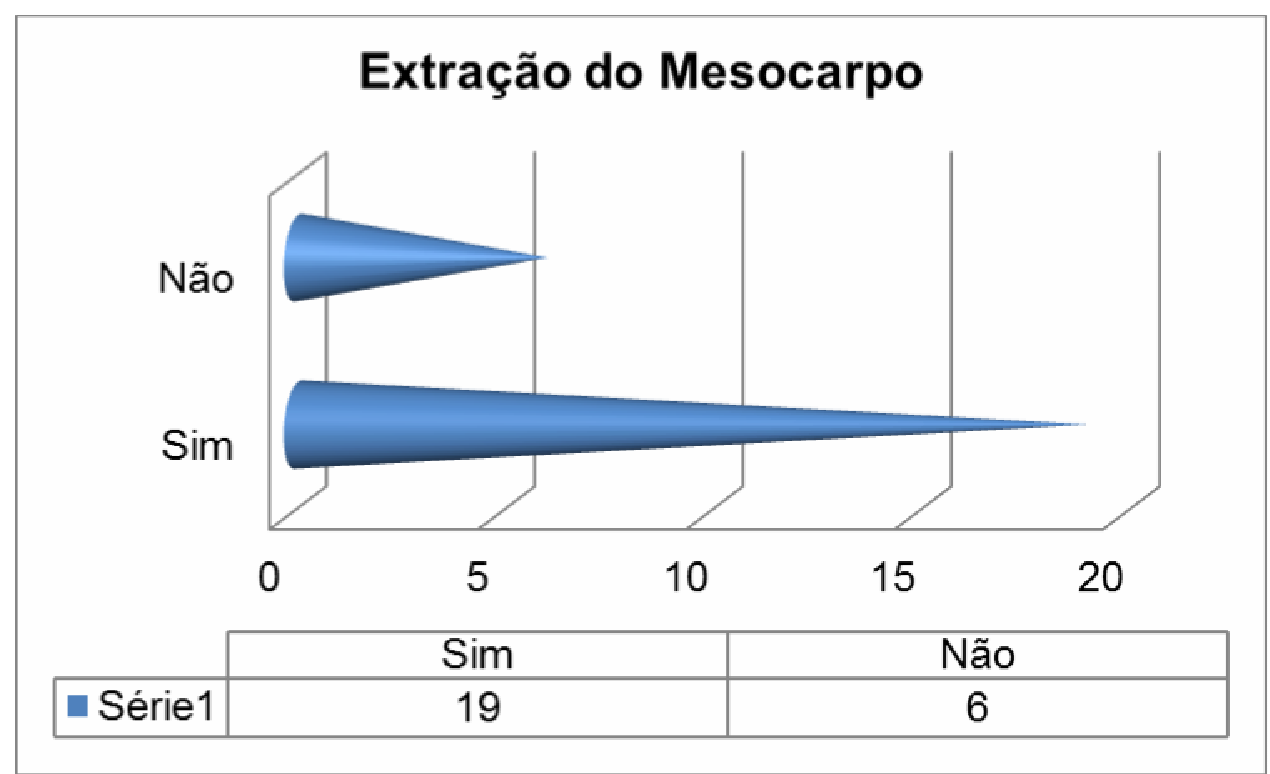

FIGURA 5. Conhecimento sobre a Extração do Mesocarpo do coco babaçu pelos alunos entrevistados.

Foi perguntado para os alunos se eles sabiam que do mesocarpo pode ser feito outros alimentos (Fig. 6), verificou-se que 72\% (19/25) dos alunos responderam que sim enquanto que $28 \%(6 / 25)$ dos alunos disseram não. Várias aplicações podem ser atribuídas ao mesocarpo do coco babaçu, no entanto, merece destaque os usos na alimentação da amêndoa e do óleo, importantes fontes de nutrientes para pessoas e animais domésticos ou de criação. É comum a produção de uma espécie de leite e de óleo comestível a partir das amêndoas, enquanto da polpa dos frutos, ou mesocarpo, produz-se a farinha de babaçu, usada como um substituto da farinha de mandioca ou como alimento para o gado. Tradicionais usos farmacêuticos AGRARIAN ACADEMY, Centro Científico Conhecer - Goiânia, v.3, n.05; p. 8 2016 
são conhecidos por essas populações, ainda que não sejam realizadas pesquisas suficientes que comprovem a aplicabilidade (COSTA, 2014).

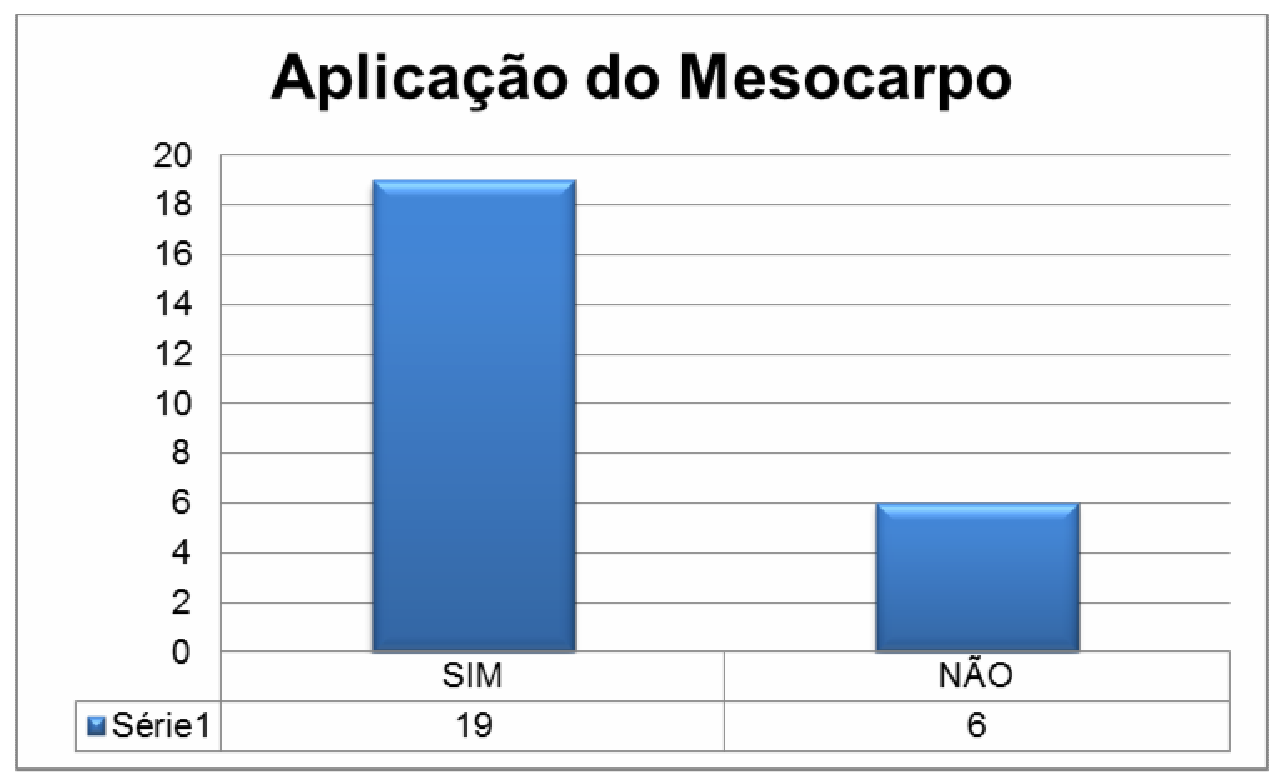

FIGURA 6. Resposta dos entrevistados quando perguntados se sabiam que o mesocarpo possuía outras aplicações

Os alunos foram questionados se tinham conhecimento que do mesocarpo poderia ser extraído vários subprodutos para a alimentação, como sorvetes, bolos, massas e outros. Verificou-se, que $76 \%$ dos alunos responderam que sim enquanto $24 \%$ responderam não (Fig. 7). Em alguns estados, o mesocarpo é comercializado em embalagens plásticas, com venda para supermercados, farmácias e lojas de produtos naturais. Os consumidores adquirem o produto e fazem usos diversos, geralmente utilizado em receitas culinárias (PINHEIRO, 2011).

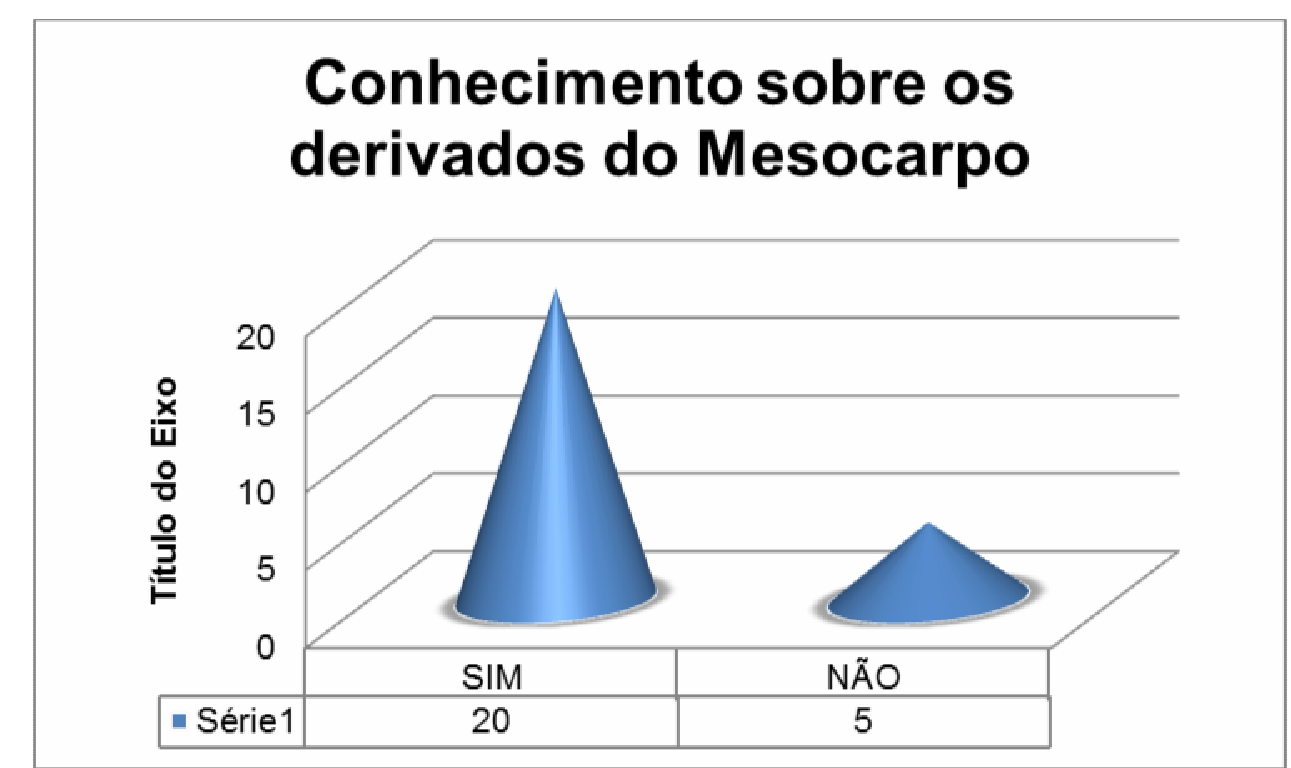

FIGURA 7. Representação do conhecimento dos alunos sobre os produtos derivados do Mesocarpo. 
Nas entrevistas aplicadas as famílias, os membros entrevistados mostraramse bastante dinâmicos e responderam com clareza e objetividade as indagações levantadas. A primeira questão foi se na atividade extrativista do coco babaçu todos os membros trabalham, os entrevistados responderam que sempre há membros das famílias trabalhando na atividade, apesar de nem sempre todos estarem presente. $O$ extrativismo do coco babaçu é concebido pelos camponeses da zona ecológica dos babaçuais como uma atividade laboral eminentemente feminina, embora também realizada por crianças do gênero masculino e, excepcionalmente, por homens jovens ou adultos (NETO, 2012).

Quando perguntados sobre o local de extração do coco, 60\% (18/30) afirmaram que são proprietários do local onde moram e 40\% (12/30) declararam ser apenas moradores. De forma unânime as famílias afirmaram que todas as partes da palmeira são aproveitadas como palha, palmito, tronco, raiz. Quando perguntadas sobre quais partes da planta utilizam como fonte de renda responderam que a parte que gera mais renda para as famílias é a venda da amêndoa do coco babaçu. PINHEIRO et al., (2010) afirmam que as folhas da palmeira são utilizadas para coberturas de casa, além de artesanatos, cercas, entre outras aplicações, além do palmito e do fruto que são absolutamente rentáveis.

Sabe-se que um dos produtos derivados do coco é o azeite, e muitas famílias produzem e vendem o mesmo. Foram perguntados como fazem o armazenamento deste produto e afirmaram que extraem o azeite e armazenam em garrafas pets. Os produtores de azeite também responderam que os principais consumidores estão na própria comunidade. Existe um Manual tecnológico do fruto e da folha do coco babaçu, neste documento são orientados a armazenar em garrrafas pets ou em vidros, o que leva a reutilização de materiais que são nocivos ao meio ambiente, esta prática incentiva a preservação ambiental. Vale lembrar que o local de armazenamento é muito importante por que o azeite se solidifica em temperaturas baixas (CARRAZZA et al., 2012).

O transporte do coco foi outro ponto discutido na entrevista realizada, e foi perguntado como era realizado o transporte do coco babaçu, os membros entrevistados responderam que para transportar o coco babaçu para suas casas é usado o cofo sendo levados na cabeça, também utilizando jumentos e burros para transporte na carga e a carroça. Em vários estados e principalmente no Maranhão e Piauí a coleta de frutos do coco babaçu é uma atividade amplamente praticada por mulheres através de cofos e homens através de jumentos e burros de carga (PINHEIRO, 2011).

A renda das famílias extrativistas é um ponto importante, e uma das perguntas realizadas era qual o valor que os produtos eram vendidos, as famílias afirmaram que os produtos oriundos do coco babaçu são vendidos da seguinte forma: amêndoas $R \$ 2,00$ o quilo, a casca a $R \$ 8,00$ a carga, o carvão a $R \$ 20,00$ o saco e o azeite a $R \$ 8,00$ o litro. O babaçu é um meio de vida, pois a economia familiar gira em torno deste produto, sendo a única fonte de renda para algumas famílias (HAGINO, 2007).

Por fim, foi indagado aos extrativistas se os mesmos tinham preocupação com a conservação do meio ambiente que era explorado, e muitos afirmaram se preocupar com o meio ambiente, pois sabe-se que devem cuidar para o próprio benefício já que outros não tem essa preocupação. Os babaçuais são utilizados na forma da lei dentro de condições que assegurem a preservação natural e do meio ambiente, e como fonte de renda ao trabalhador rural. Muito é divulgado sobre a 
preservação das matas de cocais e ainda que o manejo seja feito nos babaçuais, por pequenos agricultores, este não é dirigido a melhoria dos babaçuais, mas ao preparo da área para implantação de roças ou pastagem com efeitos positivos e negativos aos babaçuais (PINHEIRO, 2011).

Além do mesocarpo, a Associação também comercializa azeite, bolo da massa do coco, carvão, sabão e outros produtos da agricultura familiar como: feijão abobora, milho, entre outros. Os produtos são vendidos para a secretária do Desenvolvimento Rural e em feiras municipais, regionais e Interestaduais, e na própria comunidade. O extrativismo do babaçu é uma atividade que trás vários benefícios a comunidade local.

\section{CONCLUSÕES}

Com os questionários analisados, pode-se verificar que os alunos têm uma boa percepção da importância do coco babaçu. Quanto às famílias extrativistas percebeu-se que o coco babaçu é fonte de renda para as famílias e representa geração de renda, movimenta a economia local e trás benefícios econômicos e sociais para a região.

Através dos dados obtidos pode-se perceber a relevância e importância do coco babaçu para o município. O Extrativismo do coco babaçu como fonte de renda atribui valores sociais, econômicos e culturais ao município o que torna o produto como principal foco de valor para as comunidades.

Infere-se que o coco babaçu é altamente relevante para a comunidade, mas deve-se ressaltar a conservação do mesmo, pois a extração causa prejuízos drásticos para a comunidade de babaçuais, o que em escala maior pode diminuir a produtividade da mesma. Conservar é uma ação social, preservar o bem comum beneficia as gerações atuais e futuras.

\section{REFERÊNCIAS}

AROUCHA, E.P.T.L. Agricultura familiar na alimentação escolar: estudo de oportunidades e de desafios. Dissertação (Mestrado em Ecologia Humana e Gestão Socioambiental). Pós-Graduação Ecologia Humana e Gestão Socioambiental. Universidade do Estado da Bahia, p.182, 2012.

ASMPA. Livro de Ata da Associação de Moradores do Povoado Arraial. Prefeitura Municipal de São João do Arraial/PI, p. 303, 1992.

BALICK, M. J.; PINHEIRO. U. B. Babaçu (orignya pahalerata). In: CLAY, J. W.; REVILLA, J. Plantas uteis da Bacia Amazônica. Manaus: INPA/SEBRAE, v. 2, p. 444, 2002.

BARTONE, C. Relatório do Piauí. ActionAid. p. 2, 2011. Disponível em: http://187.45.205.122/Portals/0/Docs/piaui_JAN-2011.pdf Acesso em: 03/07/2016. 
BASAGLIA, P.; MARQUES, A. S.; BENATTI, L. Aceitação da Merenda Escolar entre alunos da Rede Estadual de Ensino da Cidade de Amparo-SP. Saúde em Foco. n. 7, p. 13, 2015.

CARRAZZA, L. R.; SILVA, M. L.; ÁVILA, J. C. C. Manual Tecnológico de Aproveitamento Integral do Fruto do Babaçu. Instituto Sociedade, População e Natureza. Brasília - DF, p. 68, 2012.

CARVALHO, M. G.; et al. Avaliação dos parâmetros físicos e nutricionais de amêndoas de chichá, sapucaia e castanha-do-gurguéia. Revista Ciência Agronômica. v. 39, n. 4, p. 517-523, 2009.

CASTRO, V. M. O Programa Nacional De Alimentação Escolar- PNAE como Política Pública De Desenvolvimento Sustentável. In: VIII Encontro da Sociedade Brasileira De Economia Ecológica. Anais. Cuiabá: p. 2009.

COSTA, A. K. O. Aspectos Físico-químicos e Nutricionais da Amêndoa e Óleo de Coco Babaçu (Orbignya phalerata Mart.) e avaliação sensorial de pães e biscoitos preparados com amêndoas. (Dissertação de Mestrado). Coordenação do Programa de Pós-Graduação em Ciência e Tecnologia de Alimentos. Centro de Ciências Agrárias da Universidade Federal do Ceará. p. 69, 2014.

FELIZARDO, N. Chocolate de babaçu "babalate" vira merenda escolar no Piauí. Cidade verde. $2016 . \quad$ Disponível em: http://cidadeverde.com/noticias/46531/chocolate-de-babacu-babalate-vira-merendaescolar-no-piaui Acesso em: 10/07/2016.

GIL, A. C. Métodos e técnicas de pesquisa social. 5. ed. São Paulo: Atlas, p. 220, 1999.

HAGINO, C. H. M. S. Quebradeiras de Coco Babaçu: Identidade, Conflito SócioAmbiental e Subsistência. $31^{\circ}$ Encontro Anual da ANPOCS. Universidade Federal Fluminense. Programa de Pós Graduação em Sociologia e Direito. Caxambu - MG, p. 22, 2007.

MEDEIROS, A. B.; MENDONÇA, M. J. S. L.; SOUSA, G. L.; OLIVEIRA, I. P. Importância da educação ambiental na escola nas séries iniciais. Revista Faculdade Montes Belos. v. 4, n. 1, p. 17, 2011.

NETO, N. M. S. A lei do Babaçu livre: usos e representações jurídicos das quebradeiras de coco babaçu. Perspectiva Amazônica. v. 3, n. 2, p.7-18, 2012.

NOLETO, R. A politica Nacional da Sociobiodiversidade e a cadeia do babaçu. In: CARRAZZA, L. R.; SILVA, M. L.; ÁVILA, J. C. C. Manual Tecnológico de Aproveitamento Integral do Fruto do Babaçu. Instituto Sociedade, População e Natureza. Brasília - DF, p. 68, 2012.

PINHEIRO, C. U. B. Palmeiras do Maranhão: Onde canta o sabiá. Editora Aquarela. São Luís, p.232, 2011. 
PINHEIRO, C. U. B.; ARAUJO, N. A.; AROUCHE, G. C. Plantas úteis do Maranhão: região da Baixada Maranhense. Editora Aquarela. São Luís, p. 260, 2010.

ROSA, M. V. F. P. C.; ARNOLDI, M. A. G. C. A entrevista na pesquisa qualitativa: mecanismos para a validação dos resultados. Editora Autêntica. Belo Horizonte, p. 112, 2006.

SOLER, M. P.; VITALI, A. A.; MUTO, E. F. Tecnologia de quebra do coco babaçu (Orbignya speciosa). Ciência Tecnologia de Alimentos. v. 27, n. 4, p. 717-722, 2007.

VIVA TERRA. Palmeiras Nativas do Brasil. 2013. Disponível em: http://archive.is/cUQ7A\#selection-8.18-1051.27 Acesso em: 15/04/2016. 


\section{APÊNDICE 01 \\ TERMO DE CONSENTIMENTO}

Mediante este documento a aluna Maria Eliane Mota Barroso discente do Programa de Formação de Professores da Educação Básica/PARFOR, do Curso de Licenciatura Plena em Ciências Biológicas, da Universidade Estadual do Piauí/UESPI, tendo como Orientador o Profó. Dro Gonçalo Mendes da Conceição, vem solicitar a permissão e consentimento do aluno

para realização do projeto de pesquisa na Escola Municipal Dirceu Mendes Arcoverde do Município de São João Do Arraial/PI, tendo como título de trabalho a "A IMPORTÂNCIA DO COCO BABAÇU PARA A COMUNIDADE ESCOLAR E EXTRATIVISTA NO MUNICÍPIO DE SÃO JOÃO DO ARRAIAL/PI", certo da compreensão e colaboração do responsável do aluno, pois o mesmo é menor de idade, tornando informada a mesma da aplicação deste projeto e seus eventuais efeitos.

\section{ASSINATURA DO RESPONSÁVEL}

\section{APÊNDICE 02}

\section{QUESTIONÁRIO DA ENTREVISTA APLICADA AS FAMÍLIAS EXTRATIVISTAS DO MUNICÍPIO DE SÃO JOÃO DO ARRAIAL/PI}

1. Na atividade de exploração do coco babaçu há membros da família trabalhando?

2. O local de extração do coco babaçu é de sua propriedade?

3. Quais os componentes do coco babaçu que the proporciona renda?

4. Qual o tipo de acondicionamento do azeite do coco para a venda?

5. Quais são as área de abrangência das vendas dos produtos processados do coco babaçu?

6. Quais os Meios de transporte utilizado para transportar os cocos do babaçual para a casa?

7. Qual o valor de comercializaçãolvenda dos produtos oriundos do coco babaçu? 
8. No desenvolvimento da sua atividade você tem alguma preocupação com o meio ambiente?

\section{APÊNDICE 03}

\section{QUESTIONÁRIO APLICADO AOS ALUNOS DA ESCOLA MUNICIPAL DIRCEU MENDES ARCOVERDE DO MUNICÍPIO DE SÃO JOÃO DO ARRAIAL/PI}

1) Qual o seu sexo:
( ) feminino
( ) masculino

2) Qual sua idade?

3) Qual ano você estuda?
( ) 5
( ) 6
( ) 7
( ) 8
( ) 9

4) Você sabe qual a importância do babaçu para sua comunidade?
( ) sim
) não

5) Você gosta da merenda que é servida na escola?

( ) $\operatorname{sim} \quad($ ) não

6) Você sabe de onde é extraído o mesocarpo?
( ) sim
( ) não

7) Você gosta do babalate que é servido na escola?

( ) sim ( ) não

8) Qual o sabor do babalate?
( ) bom
( ) ruim

9) Você sabe que outros alimentos podem ser feitos com o mesocarpo do babaçu?
( ) sim
( )não

10) Você sabia que do mesocarpo podemos fazer: sorvetes, bolos, massas e outros?
( ) não
( ) $\operatorname{sim}$ 